\section{Diverse modes of action of biotic and abiotic phytoalexin elicitors}

PHYTOALEXINS are inducibly formed higher plant metabolites that are antibiotic to certain potential plant pathogens ${ }^{1}$. At least 75 plant species representing 20 families have been shown to accumulate phytoalexins in response to infection ${ }^{1-3}$. Phytoalexins also accumulate in plants in response to various agents termed elicitors ${ }^{1}$, including substances of pathogen origin (biotic elicitors) and abiotic elicitors such as heavy metal salts and detergents ${ }^{1-3}$. Elicitors may be useful for investigation of the molecular basis of phytoalexin production or disease resistance expression ${ }^{1}$. However, the mechanisms by which such diverse elicitor molecules induce phytoalexin accumulation in plants are unknown. I have found ${ }^{4}$ that levels of glyceollin, a phytoalexin produced by soybean [Glycine $\max$ (L.) Merr.] hypocotyls in response to infection with the fungal pathogen Phytophthora megasperma var. sojae A. A. Hildb., are regulated by relative rates of induced biosynthesis and constitutive degrading activity. I report here the effects of various biotic and abiotic elicitors on biosynthesis and degradation of glyceollin in soybean tissues.

Detached cotyledons from 8-d-old seedlings of the soybean cultivar Harosoy 63 were wounded as described by Ayers et al. ${ }^{5}$, but wounds were made on the lower surface of the cotyledons. A $80 \mu \mathrm{l}$ drop of aqueous biotic or abiotic elicitor solution containing rifampicin and ampicillin at 10 and $500 \mu \mathrm{g} \mathrm{ml}^{-1}$, respectively, was placed on to the wounded areas of 10 cotyledons and these were incubated on moist filter papers in Petri dishes at $25^{\circ} \mathrm{C}$. Glyceollin did not accumulate in the control $\left(\mathrm{H}_{2} \mathrm{O}\right.$ treated) cotyledons (Fig. 1a) despite the fact that significant levels of biosynthetic activity were present $\sim 10 \mathrm{~h}$ after wounding (Fig. $1 b$ ). Failure of the control cotyledons to accumulate glyceollin seemed to be due to the presence of glyceollin degrading activity (Fig. 1c). Thus there was apparently a balance between synthesis and degradation, such that glyceollin did not accumulate. It would therefore be expected that glyceollin accumulation could be elicited by treatments that either inhibited its degradation and/or enhanced its synthesis to exceed the rate of degradation.

Treatment of the cotyledons with a biotic elicitor such as cell walls of Phytophthora megasperma var. sojae, a fungus highly pathogenic to certain cultivars of soybean ${ }^{1}$, greatly stimulated the glyceollin biosynthetic activity of cotyledons (Fig. 1b) and resulted in considerable accumulation (Fig. 1a). The biotic elicitor, however, had no significant effect on glyceollin degrading activity (Fig. 1c). In contrast, an abiotic elicitor such as $\mathrm{HgCl}_{2}$ also elicited glyceollin accumulation (Fig. 1a), but strongly inhibited glyceollin degrading activity of the cotyledons (Fig. 1c) with only slight effects on biosynthetic activity (Fig. 1b). These results show that the primary mechanisms of action of the biotic and abiotic elicitors are distinctly different.

All the effective abiotic elicitors of glyceollin accumulation tested, including various metals and detergents, strongly inhibited glyceollin degrading activity but their effects on synthetic activity were relatively small (Table 1 ). Some abiotic elicitors such as $\mathrm{CuSO}_{4}$ and $\mathrm{K}_{2} \mathrm{Cr}_{2} \mathrm{O}_{7}$ partially inhibited synthetic activity and glyceollin accumulation in response to these abiotic elicitors was reduced relative to those that did not inhibit synthetic activity (Table 1). High concentrations (10 $\mathrm{mM}$ ) of some abiotic elicitors such as $\mathrm{HgCl}_{2}$ and $\mathrm{CdCl}_{2}$ did not induce glyceollin accumulation, possibly because of their high toxicity to plant cells at these concentrations as indicated by strong inhibitory effects on synthetic activity. Chemicals such as $\mathrm{CoCl}_{2}$ and $\mathrm{CrCl}_{3}$ that inhibited synthetic activity more strongly than degrading activity or those such as $\mathrm{CsCl}, \mathrm{SnCl}_{4}$ and low concentrations $(0.1 \mathrm{mM})$ of $\mathrm{HgCl}_{2}$ and $\mathrm{CdCl}_{2}$, that had no significant effect on either synthetic or degrading activity were also inactive as elicitors of glyceollin accumulation. Thus, only those chemicals that selectively inhibited glyceollin degrading activity but not its synthetic activity were active abiotic elicitors.
In contrast to abiotic elicitors, none of the tested biotic elicitors of fungus origin inhibited glyceollin degrading activity, but all stimulated its synthetic activity to $\sim$ seven to eight times that in the control cotyledons (Table 1). Stimulation of the synthetic activity seemed to be caused only by biotic substances with elicitor activity, since soybean cell walls or any of the other biotic substances listed in Table 1 did not significantly affect glyceollin synthesis or accumulation. Thus the probable mechanism of action of biotic elicitors is stimulation of glyceollin synthesis to rates exceeding its rate of degradation.

Although the mechanisms underlying accumulation of phytoalexins by biotic elicitors are not understood ${ }^{1}$, my earlier observations $^{4,6-8}$ indicate that glyceollin accumulation in response to inoculation of soybeans with incompatible races of Phytophthora megasperma var. sojae may be due to increased biosynthesis resulting from de novo transcription of DNA. The present study indicates that such enhanced de novo biosynthesis may also occur in soybean after treatment with biotic elicitors, but not abiotic elicitors. The initial 'recognition' of fungal biotic elicitors by soybean cells is being studied in several laboratories $^{1,5,9,10}$

The unique response of soybean cotyledons to abiotic elicitors is significant because it offers insight into the frequently observed accumulation of plant phytoalexins in response to 'stress', that is a change in the normal physiological state of the plant cell environment. The present data clearly indicate that phytoalexin accumulation can occur in response to mechanical wounding of plant tissue in conjunction with inhibition of the normal, apparently constitutive phytoalexin degrading system.

The lack of specificity of the phytoalexin response to various abiotic elicitors has been used as an argument against a role of phytoalexins in disease resistance ${ }^{1}$. My results, however, suggest that this nonspecific phytoalexin response should be dis-
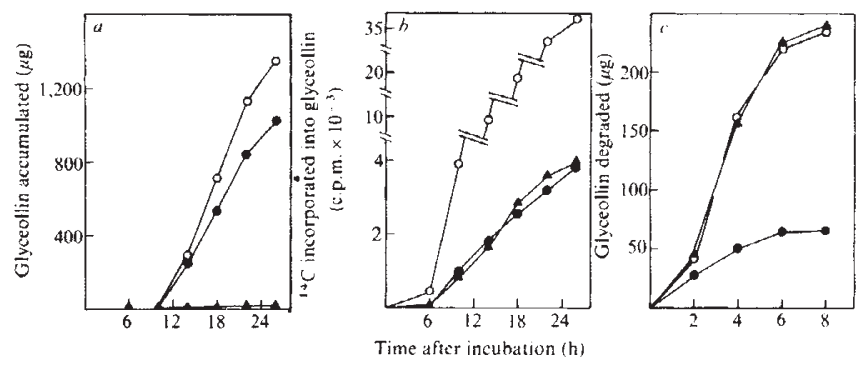

Fig. 1 Effects of $O$, a biotic elicitor [Fungal cell wall (FCW), $50 \mu \mathrm{g} \mathrm{ml}^{-1}$ ] and $\mathrm{O}$, abiotic elicitor $\left[\mathrm{HgCl}_{2}, 1.5 \mathrm{mM}\right]$ on accumulation $(a)$, synthesis $(b)$ and degradation $(c)$ of glyceollin in soybean cotyledons. For measurement of glyceollin accumulation, the wound droplets on the elicitor-treated cotyledons were collected by elution with water at various times after incubation, and glyceollin was extracted by ethylacetate ${ }^{5}$ and quantitated by a TLC/UV method ${ }^{6}$. For estimation of glyceollin biosynthetic activity in the elicitor-treated cotyledons, each wound droplet was replaced by $10 \mu \mathrm{l}$ of ${ }^{14} \mathrm{C}$-L-phenylalanine solution $\left(15 \mu \mathrm{Ci} \mathrm{ml}^{-1}\right.$, $522 \mathrm{mC} \mathrm{mmol}^{-1}$ ) at various times after incubation as indicated on the abscissa and the isotope was fed for subsequent $1 \mathrm{~h}$. The wounded sides $(\sim 1 \mathrm{~mm}$ thick) of 10 cotyledons were then collected immediately and rates of ${ }^{14} \mathrm{C}$ incorporation into glyceollin were determined by modifications of the TLC/UV method ${ }^{6}$ as described elsewhere ${ }^{4}$. For measurement of glyceollin degrading activity, eight freshly-collected cotyledons were sliced into halves parallel to their upper and lower surfaces and incubated in $50 \mathrm{ml}$ flasks containing $10 \mathrm{ml}$ of water, $300 \mu \mathrm{g}$ of purified glyceollin, antibiotics as above, and a biotic or abiotic elicitor at the indicated concentrations. The flasks were shaken at 60 strokes per min at $25^{\circ} \mathrm{C}$ for various times and glyceollin remaining undegraded in the flasks was extracted by homogenisation with $20 \mathrm{ml}$ of ethanol and quantitated ${ }^{6}$. FCW was prepared from Phytophthora megasperma var. sojae grown in a soybean hypocotyl medium ${ }^{6}$ for $5 \mathrm{~d}$ by the method of Ayers et al ${ }^{9}$ but fungal homogenate was prepared by pulverising mycelium under liquid $\mathrm{N}_{2}$ in a mortar and suspending in $0.5 \mathrm{M}$ potassium phosphate $(p \mathrm{H} 7.2)$ followed by a brief sonication ( $1 \mathrm{~min}, 5$ times). The concentration of the biotic elicitor is based on glucose equivalent by anthrone assay. $\boldsymbol{\Delta}$, Controls (water only). 
Table 1 Effects of biotic and abiotic elicitors on accumulation, synthesis, and degradation of glyceollin in soybean cotyledons

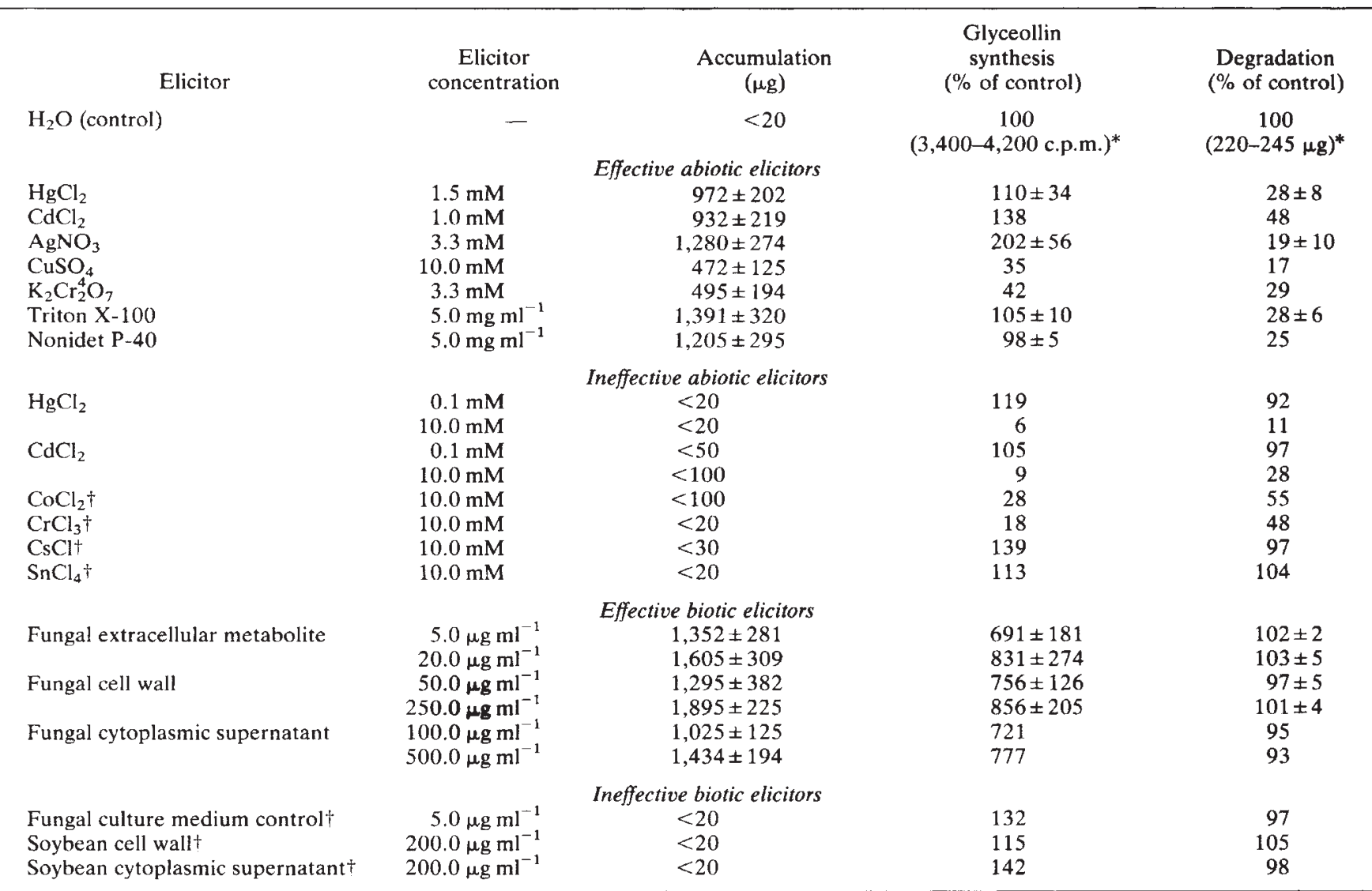

\footnotetext{
Amounts of glyceollin accumulated and degraded were measured at 24 and $8 \mathrm{~h}$, respectively, and rates of synthesis at $18 \mathrm{~h}$ after incubation of cotyledons with elicitors, as described in Fig. 1. For preparation of fungal extracellular metabolite, Phytophthora megasperma var. sojae was cultured as described in Fig. 1. After fungal mycelium was removed by filtration, the culture fluids were lyophilised, dissolved in $10 \mathrm{mM} \mathrm{Tris-} \mathrm{HCl}$ $(p \mathrm{H} \mathrm{7.2)}$, and passed through a column of Sephadex G-50 equilibrated with the same buffer. Fractions eluted in the column void volume were used. Fungal cytoplasmic supernatant was prepared by centrifuging a mycelial homogenate of the same fungus in $10 \mathrm{mM} \mathrm{Tris-} \mathrm{HCl}(p \mathrm{H} 7.2)$ at $80,000 \mathrm{~g}$ for $30 \mathrm{~min}$ and by dialysing the resulting supernatant against the same buffer. Fungal culture medium control was the fraction corresponding to the fungal extracellular metabolite fraction but the medium was not inoculated with the fungus. Soybean cell wall and cytoplasmic supernatant were prepared using the same methods described for preparation from the fungus. Means and standard errors are indicated where 3 to 5 replicate experiments were run, and other values are means of two replicate experiments.

${ }^{*}$ Actual values of incorporation of ${ }^{14} \mathrm{C}$-phenylalanine into glyceollin (c.p.m.) or of amounts of glyceollin degraded ( $\mu \mathrm{g}$ ) in the control cotyledons.

$\dagger$ Abiotic chemicals or biotic substances which did not induce glyceollin accumulation at all concentrations tested (0.033-20 mM for abiotic chemicals and $5-1,000 \mu \mathrm{g} \mathrm{ml}^{-1}$ for biotic substances). Concentrations of effective abiotic elicitors were those approximately optimum in inducing glyceollin accumulation. Concentrations of all biotic substances were based on glucose equivalents measured by anthrone assay.
}

tinguished from the specific response associated with disease resistance, as it seems that the fungal metabolites operate differently from the abiotic elicitors.

The results presented here suggest that it may be possible to discover a new type of plant protectant, protecting against infection not through intrinsic antibiotic activity, but through an effect on plant-pathogen interaction resulting in higher accumulation of phytoalexins.

This work was supported by grant 256040 from the Ministry of Education of Japan. I thank Drs N. T. Keen and H. Masago for discussions.

Faculty of Agriculture,

M. YoSHIKAWA

Kyoto Prefectural University,

Kyoto 606, Japan

Received 30 June; accepted 10 August 1978.

1. Keen, N. T. \& Bruegger, B. ACS Symp. Ser. 62, 1-26 (1977).

2. Cruickshank, I. A. Rev. Phytopathol. 1, 351-374 (1963).

3. Kuć, J. A. Rev. Phytopathol. 10, 207-232 (1972).

4. Yoshikawa, M., Yamauchi, K. \& Masago, H. Physiol. Pl. Pathol. 13 (in the press).

5. Ayers, A., Ebel, J., Finelli, F., Berger, N. \& Albersheim, P. Pl. Physiol. 57, 751-759 (1976).

6. Yoshikawa, M., Yamauchi, K. \& Masago, H. Physiol. Pl. Pathol. 12, 73-82 (1978).

7. Yoshikawa, M., Masago, H. \& Keen, N. T. Physiol. Pl. Pathol. 10, 125-138 (1977)

8. Yoshikawa, M., Yamauchi, K. \& Masago. H. Pl. Physiol. 61, 314-317 (1978).

9. Ayers, A., Ebel, J., Valent, B. \& Albersheim, P. Pl. Physiol. 57, 760-765 (1976).

10. Keen, N. T. Science 187, 74-75 (1975).

\section{The blind octopus, Cirrothauma}

THE rare deep-sea octopod Cirrothauma murrayi Chun 1910 was first described from a single specimen caught during the Michael Sars Expedition of 1910 (ref. 1). Until now it has been caught only four more times ${ }^{2}$. We describe here three specimens of this species that were recently caught during biological cruises of RRS Discovery (Fig. 1). All of these animals, including the Discovery ones, have been caught at depths of more than $1,500 \mathrm{~m}$, except one that was dip-netted through the ice of the Arctic Ocean ${ }^{3}$.

Cirrothauma belongs to a poorly known family, the Cirroteuthidae, which have cirri along the arms, a pair of fins, a deep interbrachial web and no radula ${ }^{1}$. Cirrothauma is reddishbrown semi-transparent and gelatinous in consistency (Fig. 1). Photographs of other cirroteuthids taken with deep-sea cameras have shown them swimming close to the bottom and looking like medusae, with head down and arms and web widely extended ${ }^{4.5}$. In other photographs they are swimming backwards with a more typical cephalopod posture ${ }^{5}$. 